\title{
Digital Terrain Representation Methods and Red Relief Image Map, A New Visualization Approach
}

\author{
Tatsuro Chiba $^{\text {a, }}$, Shin-ichi Kaneta ${ }^{\text {a }}$, Makoto Ohashi ${ }^{\text {a }}$ \\ ${ }^{a}$ Asia Air SurveyCo., Ltd.,ta.chiba@ajiko.co.jp,sni.kaneta@ajiko.co.jp, mkt.ohashi@ajiko.co.jp \\ * Corresponding author
}

Keywords: LiDAR, DEM, visualization, volcano

\begin{abstract}
:
Precise DEM obtained by airborne laser scanning and a global scale DEM were prepared to acquire topographic (elevation) data in recent years. For this reason, methods for visualizing the topography are increasingly required and play an significant role. However the previous terrain data representation methods were not able to represent altitude data between contour lines, and it was difficult to display altitude tints, shaded relief, and micro-topography in an easy to visualize manner. The Red Relief Image Map method shows micro-topography and major landform in one image.
\end{abstract}

\section{The problems of existing methods}

1) Contour line is difficult to represent between gentle slope and steep slope because the contour line indicates connecting points where the elevation has the same particular value.

2) Hillshade images are generated with specific lighting direction, the images have direction dependency of the image and false sense of interpreting.

3) Slope angle image map indicates the differential range of the landscape but it makes confusing ridge and valley.

4) Hypsometric tinting images are good for major landform but bad for micro-topography.

\section{Red Relief Image Map method}

The color's lightness and darkness represents degree of the ridge and valley elevation compared with neighboring elevation, positive openness and negative openness. The top-down view image is coordinated in such a way that a steeper terrain is exhibited by a vivid red color, and the color brightness determines the altitude of the terrain with respect to a reference altitude, which can be set manually. The method uses a certain type of sensory illusion to make the image stereoscopic without the aid of 3D-glasses or other special devises. ${ }^{* 1}$ Red Relief Image Map will be able to visualize the hidden surface structure of the deep-forests or interpret and analyze a variety of terrain structures such as an active volcanic crater formation, an erupted lava flow, fractures, and small crater chains (Figure 1).

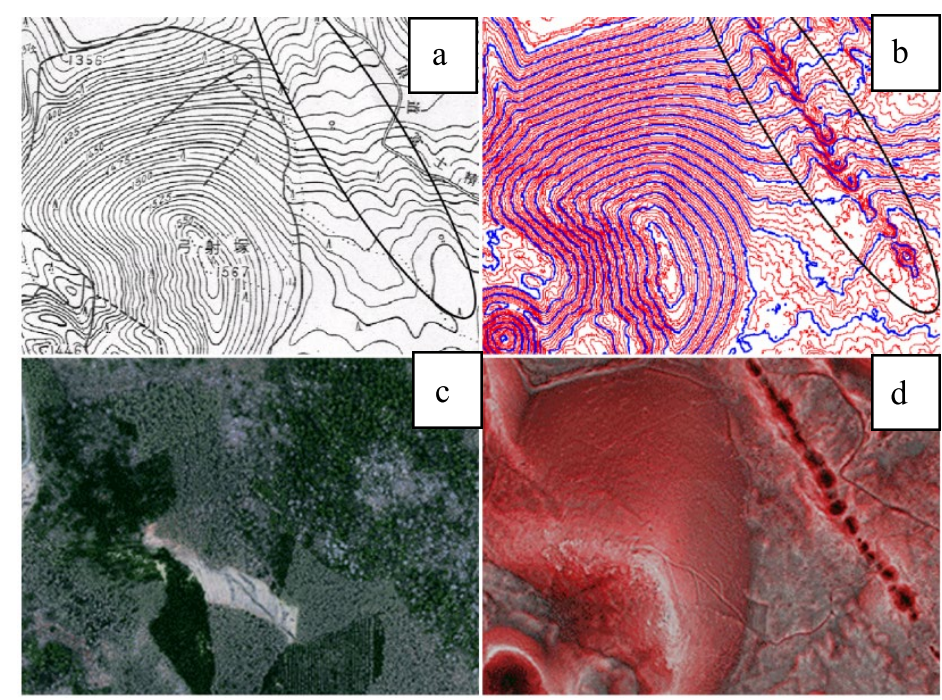

Figure 1 Topographic representation comparison of crater

a. Contour line by aerial survey, b. Contour line by LiDAR, c. Ortho image, d: Red Relief Image Map 


\section{Application examples}

1. Aso volcano, Kyushu ,Japan

The volcano erupted on October 6, 2016. Tourist facilities beside the crater were buried in ash and got some holes in the roof with ballistic projectiles. We operated UAV at $2 \mathrm{~km}$ far from the crater on December 8, 2016. The flight was $1.5 \mathrm{~km}$ distance for 15 minutes due to the battery limitation.A 3D model was constructed from 1,000 photographs with SfM structure. DSM data and orthophoto were created, and topographic interpretation was performed with the RRIM (red relief image map). The result of RRIM images indicated the deposition of ballistic projectiles near the crater, pyroclastic density current/ lahar outside the crater (Figure 2) .
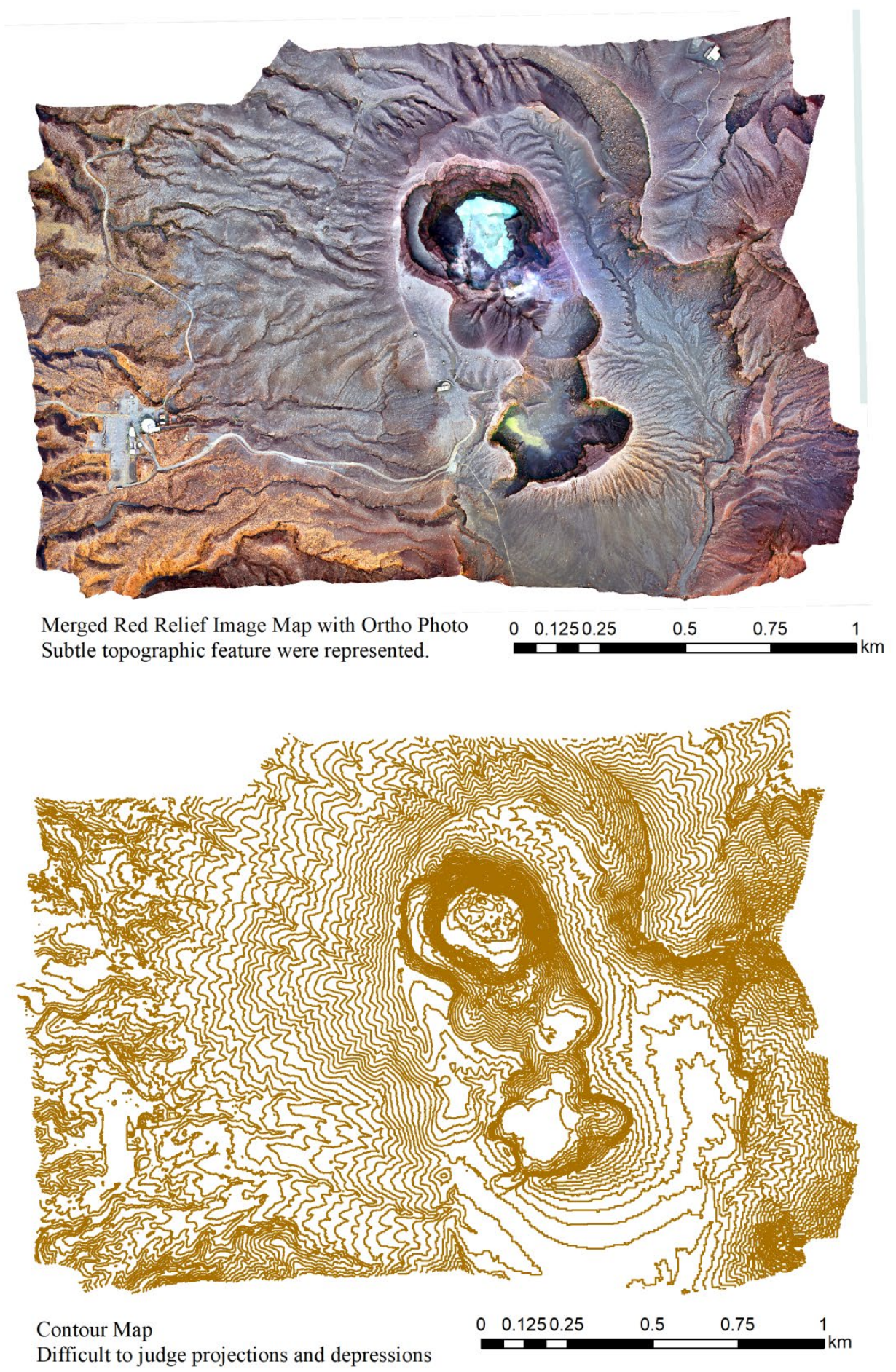

Figure 2 Comparison between versatile application of RRIM and Contour Map 


\section{Angkor Thom, Cambodia}

Red relief image map also makes it easier to understand the structure of ruins covered with jungle. The map created from LiDAR DEM is shown to reveal the fine topography of Angkor Thom archeology, Cambodia (Figure 3). The circumference of the ruins, road, and countless small ponds can be clearly expressed. ${ }^{* 2}$

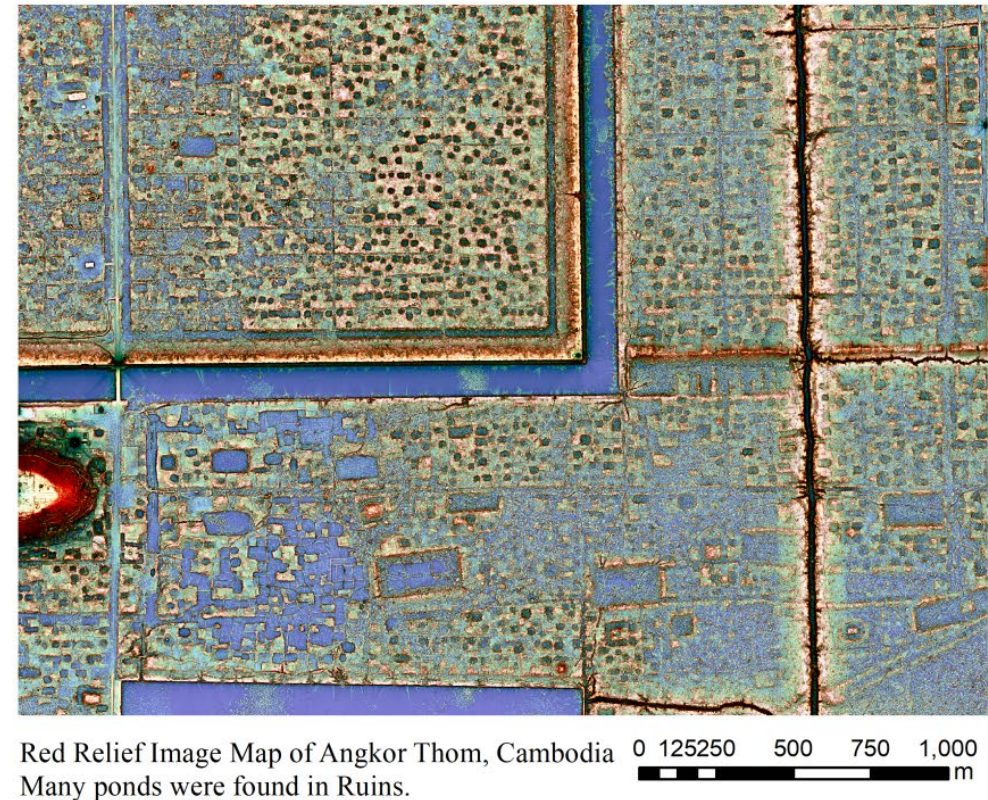
Many ponds were found in Ruins.

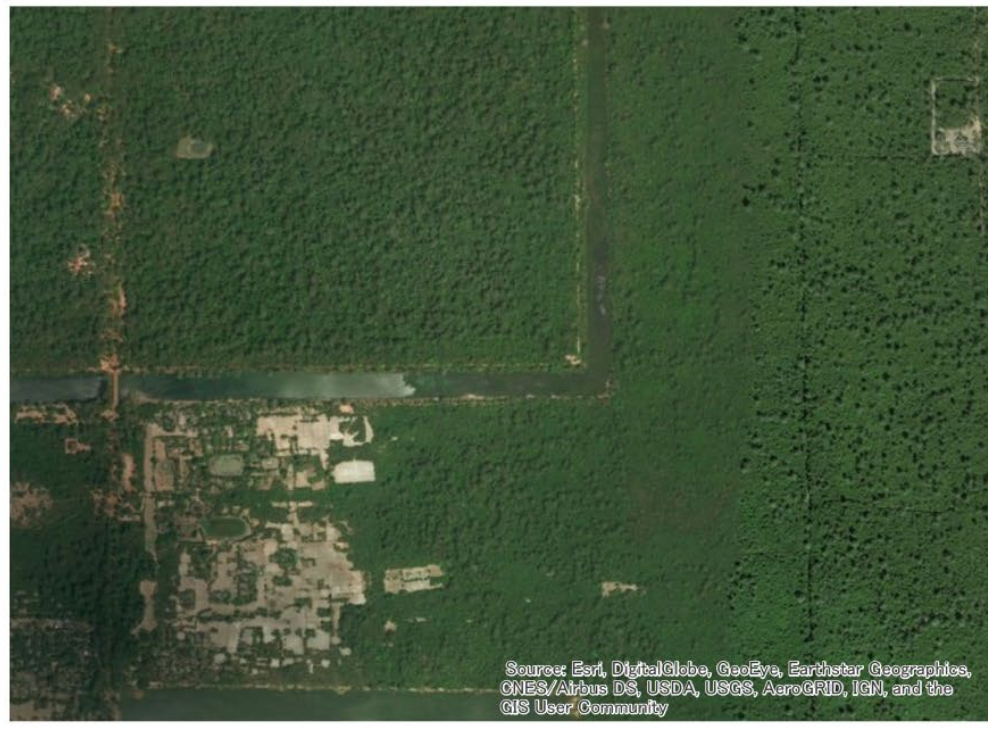

WorldView-3 Satellite image captured on 4/14/2015 $\quad \begin{array}{lllll}125250 & 500 & 750 & 1,000\end{array}$ Jungle covered the Ruins.

Figure 3 Angkor Thom Ruins hidden in the Jungle

\section{References}

*1 Tatsuro CHIBA, Shin-ichi KANETA and Yusuke SUZUKI (2008).

Red Relief Image Map: New Visualization Method for Three Dimensional Data,

ISPRS Vol. XXXVII. Part B2. Beijing

*2 Ichita SHIMODA,Tsuyoshi HARAGUCHI, Tatsuro CHIBA, Mariko SHIMODA(2016) The Advanced Hydraulic City Structure of the Royal City of Angkor Thom and Vicinity Revealed through a High-Resolution Red Relief Image Map, Archaeological Discovery,Vol4,no1,22-36. 